\title{
THE EFFECTS OF
}

\section{PROSTAGLANDINS $E_{1}, E_{2}$ AND $F_{2}$ ON VAGAL BRADYCARDIA IN THE ANAESTHETIZED MOUSE}

\author{
W. FENIUK \& B.J. LARGE \\ Department of Pharmacology, School of Medicine, Thoresby Place, Leeds LS2 9NL
}

1 In anaesthetized mice prostaglandins $E_{1}$ and $E_{2}$ reduced the bradycardia caused by electrical stimulation of the sectioned peripheral vagus nerve; prostaglandin $F_{2}$ i produced only a slight inhibition of the vagal response.

2 None of the prostaglandins studied affected acetylcholine-induced bradycardia.

3 Prostaglandins modify parasympathetic nerve activity in vivo presumably by a pre-synaptic action.

\section{Introduction}

Certain criteria must be satisfied for prostaglandins to modulate the release of autonomic neurotransmitter substances by an endogenous feedback mechanism.

In recent years, several reports have shown that prostaglandins of the $E$ series may reduce the responses of isolated cardiac preparations to both sympathetic (Hedqvist, Stjarne \& Wennmalm, 1970; Hedqvist \& Wennmalm, 1971) and parasympathetic nerve stimulation (Wennmalm \& Hedqvist, 1971; Hadhazy, Illés \& Knoll, 1973). This evidence, together with reports that prostaglandin-like substances may be released upon sympathetic (Sammuelsson \& Wennmalm, 1971) and also upon parasympathetic nerve stimulation (Coceani, Pace-Asciak, Volta \& Wolfe, 1967; Junstad \& Wennmalm, 1974), indicates a possible involvement of prostaglandins in the transmission process.

The aims of the current studies were to see whether certain prostaglandins were capable of inhibiting the effects of cardiac vagal stimulation in anaesthetized mice.

\section{Methods}

Male mice of Tuck No. 1 strain, weighing 25-40 g were anaesthetized with a mixture of chloralose $(100 \mathrm{mg} / \mathrm{kg})$ and hexobarbitone $(100 \mathrm{mg} / \mathrm{kg})$ administered via an indwelling cannula in the caudal vein which also served for all subsequent injections. The animals were artificially ventilated at 90 strokes/min, with a volume of approximately $0.5 \mathrm{ml}$. Blood pressure and integrated heart rate were measured from the cannulated left common carotid artery. On each side of the neck the cervical vagus and sympathetic nerves (Large, 1975) were separated and sectioned; bipolar platinum electrodes were used to stimulate the cardiac end of the right or left vagus with rectangular pulses of $0.5 \mathrm{~ms}$ duration at supramaximal voltage $(6-12 \mathrm{~V})$ with liquid paraffin for insulation. The initial mean arterial blood pressure was $44 \pm 2 \mathrm{mmHg}$ (mean \pm s.e.) and the initial heart rate $455 \pm 11$ beats/minute.

The vagus nerve was initially stimulated with $1 \mathrm{~Hz}$ and the frequency progressively changed through $2,5,10,20$ to $50 \mathrm{~Hz}$ as the heart rate stabilized at each frequency. The blood pressure and heart rate having returned to resting values, the vagus nerve was then stimulated intermittently with a selected frequency every $3 \mathrm{~min}$ using a constant number of shocks $(50,100$ or 200). Following two consecutive control responses, $S_{1}$ and $S_{2}$, an intravenous injection of prostaglandin $E_{1}, E_{2}$ or $F_{2 \alpha}$ was made $10-20$ s prior to obtaining the third response, $S_{3}$. The bradycardia induced by vagal stimulation in the presence of the prostaglandin was compared with that in its absence by the change in the ratios, $S_{2} / S_{1}$ and $S_{3} / S_{2}$. Differences between the ratios $S_{2} / S_{1}$ and $\mathrm{S}_{3} / \mathrm{S}_{2}$ were analysed by Student's $t$-test.

A similar procedure was adopted to investigate the effects of the prostaglandins on the bradycardia induced by intravenous acetylcholine but, in order to obtain bradycardia, physostigmine had to be given beforehand.

\section{Results}

Prostaglandins $E_{1}$ and $E_{2}$ (in doses from 2.5 to $20 \mu \mathrm{g} / \mathrm{kg}$ ) produced a fall in both systolic and 
diastolic pressures, the magnitude of which was dependent upon the resting blood pressure. In most experiments heart rate was unaffected though occasionally a tachycardia not exceeding 10 beats/min was seen. By contrast, prostaglandin $F_{2 \alpha}(10$ or $20 \mu \mathrm{g} / \mathrm{kg})$ produced a rise in both systolic and diastolic pressures, with little change in the resting heart rate.

The bradycardia induced by stimulating the cardiac end of the cut vagus nerve could be inhibited by the prior administration of prostaglandin $E_{1}$ or $E_{2}$. This inhibitory effect was of short duration, responses returning to control levels usually within a $6 \mathrm{~min}$ period. A slight inhibition of vagal bradycardia was seen with prostaglandin $F_{2 \alpha}$ although no differences were observed between the two dose levels employed. More experiments are needed to determine if larger doses of prostaglandin $F_{2 \alpha}$ could produce further inhibition. Some of these results are illustrated in Table 1. The effect of the $E$ prostaglandins was, however, dose-dependent in that progressively greater inhibition occurred as the dose was raised. A statistical analysis has only been possible so far on the results obtained with $10 \mu \mathrm{g} / \mathrm{kg}$ prostaglandin $\mathrm{E}_{1}$ and $\mathrm{E}_{2}$.

Acetylcholine $(2-5 \mu \mathrm{g} / \mathrm{kg})$ produced only vasodepression but in the presence of physostigmine salicylate $(100 \mu \mathrm{g} / \mathrm{kg})$ it caused a larger fall in blood pressure and also a bradycardia of $92 \pm 6$ beats/minute. As may be seen from Table 1 this bradycardia was unaffected by any of the prostaglandins. Physostigmine also enhanced the responses to vagal stimulation but did not modify the inhibitory effects of prostaglandin $E_{1}$ or $E_{2}$.
Since the E prostaglandins were more potent than prostaglandin $F_{2 \alpha}$ in reducing the vagal bradycardia, experiments were carried out to determine whether the inhibition was consequent upon the fall in blood pressure produced by the $\mathrm{E}$ prostaglandins. Neither bradykinin $(0.5-5 \mu \mathrm{g} / \mathrm{kg})$, which caused a prolonged fall in blood pressure, nor acetylcholine $(2-5 \mu \mathrm{g} / \mathrm{kg})$ modified the response to vagal stimulation.

\section{Discussion}

These results demonstrate that prostaglandins $E_{1}$, $E_{2}$ and, to a lesser extent, $F_{2 \alpha}$ can reduce the responses of the heart in vivo to parasympathetic nerve stimulation. These inhibitory effects appear to be presynaptic in nature.

Since the acetylcholine-induced bradycardia was unaffected by any of the prostaglandins it is tempting to conclude that these substances were preventing the release of acetylcholine from the parasympathetic nerve endings, though an effect on ganglionic transmission cannot be excluded. Vasodepression as such was not responsible for the inhibitory effect of the $E$ prostaglandins since neither bradykinin nor acetylcholine were capable of reducing the responses to vagal stimulation. Furthermore larger doses of E prostaglandins, which did not always produce a greater fall in blood pressure, caused a greater inhibition of the bradycardia.

Benz \& Salzmann (1974) stated that prostaglandins did not modify vagal activity in the anaesthetized cat, despite observing a small

Table 1 Effect of intravenous prostaglandins (PGs) on the bradycardia induced in anaesthetized mice either by electrical stimulation of the vagus nerve or by acetylcholine

\begin{tabular}{|c|c|c|c|c|c|c|c|c|c|}
\hline & $\begin{array}{c}\text { Mean } \\
\Delta H R\end{array}$ & $\begin{array}{l}\text { Control } \\
\qquad S_{2} / s_{1} \dagger\end{array}$ & $\mathbf{n}$ & $\begin{array}{c}P G E_{1} \\
(10 \mu g / k g) \\
S_{3} / S_{2}\end{array}$ & $\mathbf{n}$ & $\begin{array}{c}P G E_{2} \\
(10 \mu g / k g) \\
S_{3} / S_{2}\end{array}$ & $n$ & $\begin{array}{c}P G F_{2 \alpha} \\
110 \text { or } 20 \mu g / k g \\
S_{3} / S_{2}\end{array}$ & g) \\
\hline \multicolumn{10}{|l|}{$¥$ Acetylcholine } \\
\hline $\begin{array}{l}2 \text { to } 5 \mu \mathrm{g} / \mathrm{kg} \\
10 \mathrm{~Hz} 5 \mathrm{~s}\end{array}$ & $\begin{array}{l}92 \\
88\end{array}$ & $\begin{array}{l}0.97 \pm 0.02 \\
0.97 \pm 0.02\end{array}$ & 12 & $0.99 \pm 0.04$ & 6 & $0.97 \pm 0.09$ & 3 & $\begin{array}{l}1.02 \pm 0.04 \\
0.95 \pm 0.03\end{array}$ & $\begin{array}{l}3 \\
4\end{array}$ \\
\hline $10 \mathrm{~Hz} 10 \mathrm{~s}$ & $\begin{array}{r}00 \\
124\end{array}$ & $1.03 \pm 0.02$ & 20 & $0.38 \pm 0.12^{* * *}$ & $\begin{array}{l}4 \\
6\end{array}$ & $0.36 \pm 0.06^{* * *}$ & $\begin{array}{l}4 \\
8\end{array}$ & $0.92 \pm 0.03 * *$ & 6 \\
\hline $20 \mathrm{~Hz} 5 \mathrm{~s}$ & 125 & $1.05 \pm 0.01$ & 7 & $0.53 \pm 0.13^{* * *}$ & 3 & $0.54 \pm 0.08^{* * *}$ & 4 & - & \\
\hline $20 \mathrm{~Hz} 10 \mathrm{~s}$ & 137 & $0.99 \pm 0.04$ & 8 & $0.55 \pm 0.16^{* *}$ & 3 & $0.39 \pm 0.11^{* * *}$ & 5 & - & \\
\hline $50 \mathrm{~Hz} 2 \mathrm{~s}$ & 272 & $1.04 \pm 0.03$ & 5 & 0.25 & 2 & $0.62 \pm 0.13^{*}$ & 3 & - & \\
\hline
\end{tabular}

All values are means \pm s.e. mean. $+S_{1}$ and $S_{2}$ are two successive control responses just prior to $S_{3}$ which is the response obtained 10 to $20 \mathrm{~s}$ after injection of the prostaglandin. $¥$ Responses to acetylcholine were obtained after the administration of physostigmine salicylate $(100 \mu \mathrm{g} / \mathrm{kg})$ both drugs being given intravenously.

Comparison of ratio $S_{2} / S_{1}$ with appropriate $S_{3} / S_{2}$; Student's $t$ test, $P$ values: $*<0.05>0.01$; ** $<0.01>0.001 ; * * *<0.001$. There were no statistically significant differences between any pairs of $\mathrm{S}_{3} / \mathrm{S}_{2}$ values for a given prostaglandin during the periods of nerve stimulation. 
reduction in the magnitude of the vagal bradycardia with prostaglandins $E_{1}$ or $F_{2 \alpha}$, whilst $\mathrm{E}_{2}$ was without activity. Although species differences may exist, a direct comparison of results is difficult, since in their experiments the prostaglandins were given by intravenous infusion at rates from 0.001 to $1.0 \mu \mathrm{g} /$ minute.

Our results suggest that prostaglandins, particularly of the E series, may modulate the release of

\section{References}

BENZ, M. \& SALZMANN, R. (1974). The effects of $\mathrm{PGE}_{1}, \mathrm{PGE}_{2}$ and $\mathrm{PGF}_{2} \alpha$ on parasympathetic transmission. Arch. Pharmac., 282, Suppl. R7.

COCEANI, F., PACE-ASCIAK, F., VOLTA, F. \& WOLFE, L.S. (1967). Effect of nerve stimulation on prostaglandin formation and release from the rat stomach. Amer. J. Physiol., 213, 1056-1064.

HADHAZY, P., ILLÉS, P. \& KNOLL, J. (1973). The effects of $\mathrm{PGE}_{1}$ on responses to cardiac vagus nerve stimulation and acetylcholine release. Eur. $J$. Pharmac., 23, 251-255.

HEDQVIST, P., STJARNE, L. \& WENNMALM, A. (1970). Inhibition by prostaglandin $E_{2}$ of sympathetic neurotransmission in the rabbit heart. Acta physiol. scand., 79, 139-141.

HEDQVIST, P. \& WENNMALM, A. (1971). Comparison of the effects of prostaglandins $E_{1}, E_{2}$ and $F_{2 \alpha}$ on the sympathetically stimulated rabbit heart. Acta physiol. scand., 83, 156-162. the parasympathetic neurotransmitter and demonstrate that inhibitory effects can occur in vivo.

At present we are studying the effects of prostaglandin-synthetase inhibitors on this phenomenon and also the actions of prostaglandins on sympathetic function in mice.

W.F. is an MRC scholar. The prostaglandins were kindly provided by Dr J.E. Pike of the Upjohn Company, Kalamazoo, U.S.A.

JUNSTAD, M. \& WENNMALM, A. (1974). Release of prostaglandin from the rabbit isolated heart following vagal nerve stimulation or acetylcholine infusion. $\mathrm{Br}$. J. Pharmac., 52, 375-379.

LARGE, B.J. (1975). Innervation both of peri-orbital structures and of the heart by the cervical sympathetic nerves in mouse, rat, guinea-pig, rabbit and cat. $B r . J$. Pharmac., 54, 351-358.

SAMMUELSSON, B. \& WENNMALM, A. (1971). Increased nerve stimulation induced release of noradrenaline from the rabbit heart after inhibition of prostaglandin synthesis. Acta physiol. scand., 83, 163-168.

WENNMALM, A. \& HEDQVIST, P. (1971). Inhibition by prostaglandin $E_{1}$ of parasympathetic neurotransmission in the rabbit heart. Life Sci., 10, 465-470.

(Received April 4, 1975. Revised June 12,1975.) 